Article

\title{
Further Investigation of the Mediterranean Sponge Axinella polypoides: Isolation of a New Cyclonucleoside and a New Betaine
}

\author{
Marialuisa Menna ${ }^{1{ }^{*} *}$, Anna Aiello ${ }^{1}$, Filomena D’Aniello ${ }^{1}$, Ernesto Fattorusso ${ }^{1, \dagger}$, \\ Concetta Imperatore ${ }^{1}$, Paolo Luciano ${ }^{2}$ and Rocco Vitalone ${ }^{1}$
}

1 The NeaNat Group, Department of Chemistry of Natural Products, University of Naples "Federico II",

Via D. Montesano 49, Napoli 80131, Italy; E-Mails: aiello@unina.it (A.A.);

filomena.daniello@unina.it (F.D.); fattoru@unina.it (E.F.); cimperat@unina.it (C.I.); rocco.vitalone@unina.it (R.V.)

2 C.S.I.A.S. (Interdepartmental Center of Instrumental Analysis), University of Naples "Federico II", Via D. Montesano 49, Napoli 80131, Italy; E-Mail: pluciano@unina.it

$\dagger$ Deceased on 7 July 2012.

* Author to whom correspondence should be addressed; E-Mail: mlmenna@unina.it; Tel.: +39-081-678-518; Fax: +39-081-678-552.

Received: 12 September 2012; in revised form: 26 October 2012 / Accepted: 30 October 2012 / Published: 9 November 2012

\begin{abstract}
An exhaustive exploration into the metabolic content of the Mediterranean sponge Axinella-polypoides resulted in the isolation of the new betaine $\mathbf{5}$ and the new cyclonucleoside $\mathbf{8}$. The structures of the new metabolites were elucidated by spectroscopic methods assisted by computational methods. The analysis also provided evidence that the sponge does not elaborate pyrrole-imidazole alkaloids (PIAs) but, interestingly, it was shown to contain two already known cyclodipeptides, compounds 9 (verpacamide A) and $\mathbf{1 0 .}$
\end{abstract}

Keywords: natural products; sponges; Axinellidae; pyrrole-imidazole alkaloids; taxon-specificity

\section{Introduction}

Diverse natural products found within sponges mediate many of their ecological interactions, including defense against predators and fouling organisms. Marine sponges of genus Axinella are an 
interesting target for chemo-ecological investigations. They are a well-known source of pyrrole-imidazole alkaloids (PIAs), which have been found only in the marine environment to date. Historically, this family of alkaloids has attracted the attention of natural product chemists because of their structural complexity and pharmacological activity; their role in chemically mediated interactions of Caribbean sponges has also been proven [1,2]. In addition, the systematic recurrence of PIAs in Axinellidae sponges, as well as in Agelasidae, allowed for speculation as to their taxon-specificity and consideration of these secondary metabolites as chemical markers for phylogenetically related sponges [3]. However, the setting up of a chemical "fingerprint" of a sponge, collected from different ecosystems, requires exhaustive chemical studies. An illustrative example is the sponge Axinella polypoides (Schmidt 1862), widely distributed in the rock reefs of the Mediterranean Sea. Early studies are reported in literature on the chemistry of this sponge, mainly concerning its steroid and lectin content [4-8]; actually, recent re-examinations of samples of A. polypoides, coming from different Mediterranean areas, demonstrated that the sponge has an efficient biosynthetic potential, revealing a great variety and abundance of secondary metabolites, some of them being new molecules (Figure 1). In detail, two new modified amino acids, axiphenylalaninium (1) and axityrosinium (2), were found in specimens of the sponge collected off Marseille city [9] along with the known metabolites

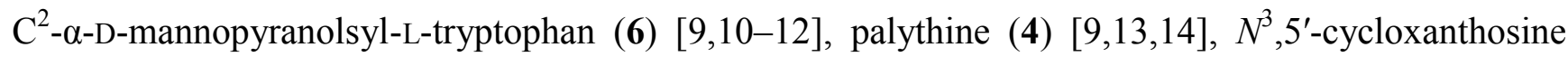
(7) $[9,11,15]$, and taurine $[9,16]$; no data was reported on the presence of PIAs in the sponge. Successively, during our ongoing search for new bioactive alkaloids from Axinellidae sponges, we have isolated compounds $\mathbf{1}$ and $\mathbf{2}$ in specimens of $A$. polypoides collected along Corsican coasts, together with a new betaine, polyaxibetaine (3) [17].

Figure 1. Secondary metabolites isolated from A. polypoides.
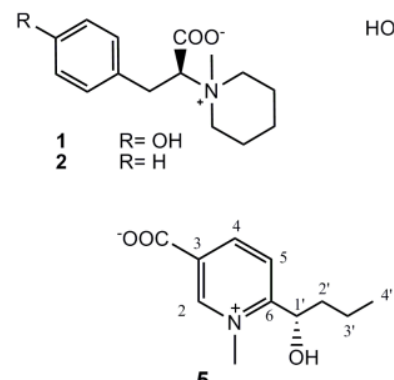

5
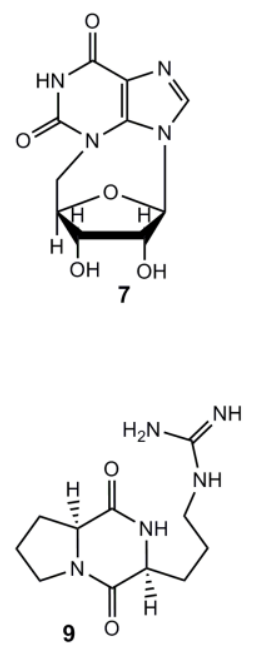
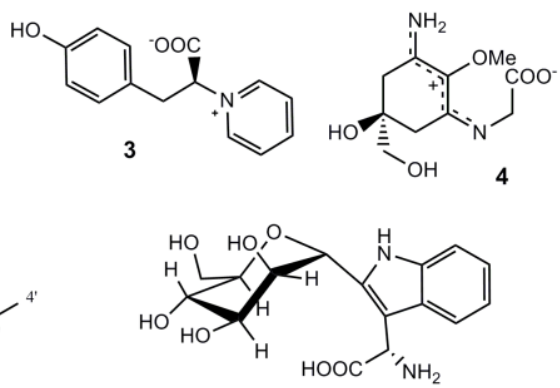

6
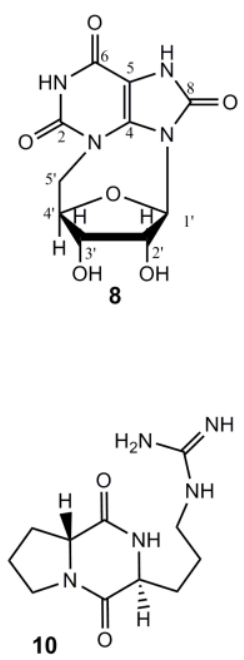
In the present communication we describe the results obtained from a further and more exhaustive exploration into the metabolic content of a larger sample of $A$. polypoides, which resulted in the isolation of a new pyridinium derivative, compound $\mathbf{5}$, and the new cyclonucleoside $\mathbf{8}$. All the previously reported secondary metabolites from the sponge were re-isolated, except for palythine (4). We did not find any member of the PIAs family in the sponge extract but, interestingly, it was shown to contain the already known cyclodipeptides 9 (verpacamide A) and 10. The cyclo(L-Arg-D-Pro) dipeptide 10 was first isolated from a marine bacterium, Pseudomonas sp. IZ208 [18]; the relevant cyclo(L-Arg-L-Pro) stereoisomer, verpacamide A (9), was first reported as a natural metabolite of the sponge Axinella vaceleti along with the analogues verpacamides B-D and these metabolites were considered as possible precursors of PIAs [19].

\section{Results and Discussion}

Specimens of $A$. polypoides were collected in the bay of Calvi (Corsica, France), they were immediately frozen after collection, and kept at $-20{ }^{\circ} \mathrm{C}$ until extraction. For the extraction, fresh thawed tissues of the sponge were homogenized and exhaustively extracted at room temperature with $\mathrm{MeOH}$ and $\mathrm{CHCl}_{3}$ successively. The extracts were combined and concentrated; the resulting aqueous suspension was then partitioned between butanol and $\mathrm{H}_{2} \mathrm{O}$. Both organic and aqueous layers were fractionated by MPLC over a reversed-phase C-18 column and by DCCC, respectively. All the fractions thus obtained were subjected to a combined NMR/ESIMS-based monitoring for the rapid identification of PIAs, also exploiting, as reference compounds, the copious chemical library of these alkaloids available in our laboratories. None of the already described PIAs was detected; fractions of interest were separated by repeated HPLC, resulting in the isolation of pure compounds 1-3 and 5-10. Taurine, as well as compounds $\mathbf{1 - 3}, \mathbf{6}, \mathbf{7}, \mathbf{9}$, and $\mathbf{1 0}$ were readily identified by comparison of their spectroscopic data with those reported in literature [9-17], while the structures of the new compounds $\mathbf{5}$ and $\mathbf{8}$ were established as follows.

HRESI mass spectrum (positive ions) of 5 revealed two pseudomolecular ion peaks at $\mathrm{m} / \mathrm{z} 210.1130$ and 232.0950, corresponding to $[\mathrm{M}+\mathrm{H}]^{+}$(calculated value: 210.1125 ), and $[\mathrm{M}+\mathrm{Na}]^{+}$(calculated value: 232.0944), respectively. The molecular formula $\mathrm{C}_{11} \mathrm{H}_{15} \mathrm{NO}_{3}$ was thus established for 5, indicating five unsaturation degrees. ${ }^{1} \mathrm{H}-\mathrm{NMR}$ spectrum of $5\left(\mathrm{CD}_{3} \mathrm{OD}\right)$, interpreted on the basis of $2 \mathrm{D}$ experiments (HSQC, COSY) contained a set of aromatic signals, each integrating for one proton; the chemical shift and coupling constants values of these signals $\left[\delta 9.10\left(\mathrm{bs}, \delta_{\mathrm{C}}=148.7, \mathrm{H}-2\right) ; 8.84\right.$ (bd, $\left.\left.J=8.2 \mathrm{~Hz}, \delta_{\mathrm{C}}=146.3, \mathrm{H}-4\right) ; 8.19\left(\mathrm{~d}, J=8.2 \mathrm{~Hz}, \delta_{\mathrm{C}}=126.6, \mathrm{H}-5\right)\right]$ were strongly indicative of a 1,2,5-trisubstituted pyridinium ring. Further proton resonances were a deshielded methine at $\delta 5.13$ $\left(\mathrm{dd}, J=9.0,3.3 \mathrm{~Hz}, \delta_{\mathrm{C}}=69.3, \mathrm{H}-1^{\prime}\right)$, two AB methilene systems at $\delta 1.72 / 1.81\left(\delta_{\mathrm{C}}=38.9,2 \mathrm{H}-2^{\prime}\right)$ and $1.54 / 1.63\left(\delta_{\mathrm{C}}=19.9,2 \mathrm{H}-3^{\prime}\right)$, as well as a methyl resonating as a triplet at $\delta 1.00\left(J=7.5 \mathrm{~Hz}, \delta_{\mathrm{C}}=14.0\right.$, $\left.3 \mathrm{H}-4^{\prime}\right)$, which were arranged in a single spin system on the basis of COSY connectivities. The signal at $\delta 5.13$ was correlated in the HSQC spectrum with a signal at $\delta 69.3$ attributable to an oxygen bearing carbon, thus evidencing a 1-hydroxybutyl unit.

An N-methyl signal $\delta 4.38\left(\delta_{\mathrm{C}}=46.1\right)$ was also present in the proton spectrum of 5; it was correlated in the ROESY spectrum $\left(\mathrm{CD}_{3} \mathrm{OD}\right)$ with the aromatic proton singlet at $\delta 9.10(\mathrm{H}-2)$ and with the oxymethine proton at $\delta 5.13\left(\mathrm{H}^{-1} 1^{\prime}\right)$. This latter information, according to the coupling constants 
pattern of the aromatic signals, provided convincing evidence for an N-methyl-2,5-disubstituted pyridinium ring and indicated that the 1-hydroxybutyl unit must be linked at one of the N-flanking carbons. Diagnostic $\mathrm{C}-\mathrm{H}$ long range couplings, evidenced by $\mathrm{HMBC}$ map $\left(\mathrm{CD}_{3} \mathrm{OD}\right.$, see Table 1$)$, substantiated the proposed structural features and allowed to identify the third substituent, obviously liked at C-3.

Table 1. NMR data $\left(\mathrm{CD}_{3} \mathrm{OD}\right)$ of compound 5.

\begin{tabular}{cccc}
\hline Position & $\boldsymbol{\delta}_{\mathbf{H}}$ (mult., $\boldsymbol{J}$ in Hz) & $\boldsymbol{\delta}_{\mathbf{C}}$ & HMBC \\
\hline $1-\mathrm{NMe}$ & $4.38(\mathrm{~s})$ & 46.1 & 2,6 \\
2 & $9.10(\mathrm{bs})$ & 148.7 & $1-\mathrm{NMe}, 4,6, \mathrm{COO}^{-}$ \\
3 & - & 137.8 & - \\
4 & $8.84(\mathrm{bd}, 8.2)$ & 146.3 & $2,6, \mathrm{COO}^{\prime} \mathrm{Na}^{+}$ \\
5 & $8.19(\mathrm{~d}, 8.2)$ & 126.6 & $3,6,1^{\prime}$ \\
6 & - & 163.0 & - \\
$1^{\prime}$ & $5.13(\mathrm{dd}, 3.3,9.0)$ & 69.3 & $6,2^{\prime}$ \\
$2^{\prime}$ & $1.72(\mathrm{~m})$ & 38.9 & $6,1^{\prime}, 3^{\prime}, 4^{\prime}$ \\
& $1.81(\mathrm{~m})$ & & \\
$3^{\prime}$ & $1.54(\mathrm{~m})$ & 19.9 & $1^{\prime}, 2^{\prime}, 4^{\prime}$ \\
$4^{\prime}$ & $1.63(\mathrm{~m})$ & 14.0 & $2^{\prime}, 3^{\prime}$ \\
$-\mathrm{COO}^{-}$ & $1.00(\mathrm{t}, 7.5)$ & 167.0 & - \\
\hline
\end{tabular}

Particularly, the N-methyl signal at $\delta 4.38$ was correlated to the carbon at $\delta 148.7(\mathrm{C}-2)$ and a quaternary carbon at $\delta 163.0(\mathrm{C}-6)$ which, in turn, was coupled to the signal at $\delta 5.13\left(\mathrm{H}-1^{\prime}\right)$ and 8.19 (H-5); the latter signal was correlated with the oxymethine carbon at $\delta 69.3\left(\mathrm{C}-1^{\prime}\right)$ and the quaternary carbons at $\delta 163.0(\mathrm{C}-6)$ and 137.8 (C-3). Moreover, both aromatic signals at $\delta 9.10(\mathrm{H}-2)$ and $8.84(\mathrm{H}-4)$ were coupled to a low-field carbon resonance at $\delta 167.0$, attributable to a carbonyl; this datum, according to the mass data, allowed to locate a carboxylate function at $\mathrm{C}-3$, thus accounting for the last unsaturation degree indicated by the molecular formula. Therefore, the planar structure of compound 5 was unambiguously defined as 6-(1-hydroxybutyl)-1-methylpyridinium-3-carboxylate.

Absolute configuration (AC) of compound 5 was established with the help of electronic circular dichroism (ECD) spectroscopy assisted by quantum mechanical calculations. The application of ab initio time-dependent density functional theory (TDDFT) to the calculation of ECD spectra has greatly enhanced the reliability with which they can be predicted and, thus, this methodology is being increasingly utilized in determining ACs of natural products [17,20-22]. The experimental ECD spectrum of 5 was virtually compared to that predicted by TDDFT calculations for one of the two enantiomers. In detail, an initial conformational analysis of the $S$ stereoisomer was performed, using the Simulated Annealing procedure (INSIGHT II Software Package). The resulting conformers were ranked on the basis of their conformational energy values and grouped into families. Twelve minima for $S$-5 were obtained and all conformers were optimized with the software package Gaussian 03 [23] by using DFT at the RB3LYP/6-31G(d) level (the conformational families of $S$-5, as well as their resulting relative $(\Delta \mathrm{E})$ and free $(\Delta \mathrm{G})$ energies, are provided as Supporting Information). For all conformers of $S \mathbf{- 5}$, the excitation energies, as well as the oscillator and rotatory strengths of the 
electronic excitation were calculated, using the TDDFT methodology at the RB3LYP/6-31G(d,p) level; their ECD spectra were then simulated by the overlapping Gaussian function. To obtain the final ECD spectrum of each compound, the simulated spectra of the lowest energy conformations were averaged, by following the Boltzmann statistic, and were UV corrected. The theoretical curve was then compared to the experimental spectrum of compound 5, recorded in $\mathrm{MeOH}$. As shown in Figure 2, the agreement between the simulated and experimental ECD spectra of $\mathbf{5}$ was very satisfactory and, thus, the absolute configuration of 1 was established as $S$.

Figure 2. Theoretical CD curve (-) of S-5 model vs. experimental curve (-) of compound $\mathbf{5}$.

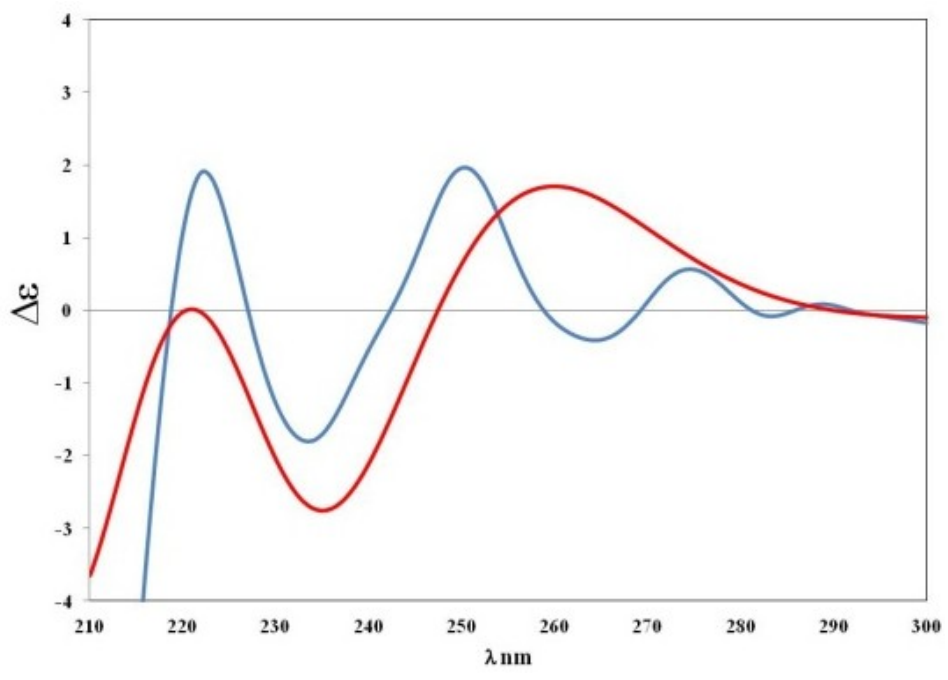

A pseudomolecular peak was present in the HRESI mass spectrum (positive ions) of $\mathbf{8}$ at $\mathrm{m} / \mathrm{z} 283.0673[\mathrm{M}+\mathrm{H}]^{+}$(calculated value: 283.0679), thus supporting the molecular formula $\mathrm{C}_{10} \mathrm{H}_{10} \mathrm{~N}_{4} \mathrm{O}_{6}$. ${ }^{1} \mathrm{H}$-and ${ }^{13} \mathrm{C}$-NMR spectral data of 8 strongly resembled those of the known cyclonucleoside 7 (see Table 2 ). The proton spectrum of $\mathbf{8}\left(d_{6}\right.$-DMSO) contained indeed resonances relevant to a sugar moiety which were nearly identical to those of 7 , with regard to the number and shape of the signals (see Table 2); the striking difference was confined to the chemical shift value of the anomeric proton $\left(\mathrm{H}-1^{\prime}, \delta 5.67\right.$ in 8 versus 6.15 in 7). As for the heterocyclic moiety, the ${ }^{1} \mathrm{H}-\mathrm{NMR}$ spectrum of 8 lacked the signal due to the single aromatic proton of xanthosine present in that of 7 at $\delta 7.79$ but a further exchangeable proton at $\delta 11.2$ (NH-7) was present. On the other hand, ${ }^{13} \mathrm{C}-\mathrm{NMR}$ spectrum $\left(d_{6}\right.$-DMSO), interpreted also on the basis of the HSQC experiment, contained a further deshielded quaternary carbon resonance at $\delta 149.6$ instead of the C-8 methine carbon resonating at $\delta$ 134.5 in the ${ }^{13} \mathrm{C}$-NMR spectrum of 7. All these findings indicated the 8 -oxo- $N^{3}, 5$-cycloxanthosine structure for compound $\mathbf{8}$, according to MS data and HMBC correlations (see Table 2). 
Table 2. NMR data $\left(d_{6}\right.$-DMSO) of compounds 7 and $\mathbf{8}$.

\begin{tabular}{|c|c|c|c|c|c|}
\hline \multirow{2}{*}{ Position } & \multicolumn{2}{|r|}{7} & \multicolumn{3}{|c|}{8} \\
\hline & $\boldsymbol{\delta}_{\mathrm{C}}$ & $\delta_{\mathrm{H}}(J$ in $\mathrm{Hz})$ & $\boldsymbol{\delta}_{\mathrm{C}}$ & $\delta_{\mathrm{H}}(J$ in $\mathrm{Hz})$ & HMBC $^{\text {a }}$ \\
\hline 1 & - & - & - & - & - \\
\hline 2 & 151.0 & - & 150.7 & - & - \\
\hline 3 & - & - & - & - & - \\
\hline 4 & 140.7 & - & 136.8 & - & - \\
\hline 5 & 117.8 & - & 98.8 & - & - \\
\hline 6 & 157.4 & - & 153.4 & - & - \\
\hline 7 & - & - & - & - & - \\
\hline 8 & 134.5 & $7.79(\mathrm{~s})$ & 149.6 & - & - \\
\hline 9 & - & - & - & - & - \\
\hline $1^{\prime}$ & 92.5 & $6.15(\mathrm{~s})$ & 91.1 & $5.67(\mathrm{~s})$ & $4,8,2^{\prime}, 3^{\prime}, 4^{\prime}$ \\
\hline $2^{\prime}$ & 75.8 & $3.87(\mathrm{dd}, 5.2,5.0)$ & 75.0 & $3.90(t, 5.3)$ & $1^{\prime}, 4^{\prime}$ \\
\hline $3^{\prime}$ & 70.1 & $4.20(\mathrm{~m})$ & 70.7 & $4.23(\mathrm{~m})$ & $5^{\prime}$ \\
\hline $4^{\prime}$ & 83.7 & $4.55(\mathrm{~m})$ & 83.6 & $4.46(\mathrm{~m})$ & - \\
\hline $5^{\prime} \mathrm{a}$ & 51.3 & $4.56(\mathrm{~m})$ & 52.3 & $\begin{array}{c}4.51(\mathrm{dd}, 14.4 \\
2.4)\end{array}$ & $2,4,3^{\prime}, 4^{\prime}$ \\
\hline $5 \mathrm{~b}$ & 51.3 & $3.71(\mathrm{dd}, 15.2,3.2)$ & 52.3 & $3.72(\mathrm{dd}, 14.4,2.8)$ & $2,4,3^{\prime}, 4^{\prime}$ \\
\hline $\mathrm{OH}-2^{\prime}$ & - & $5.62(\mathrm{~d}, 5.0)$ & - & $5.60(\mathrm{~d}, 5.3)$ & - \\
\hline $\mathrm{OH}-3^{\prime}$ & - & $5.62(\mathrm{bs})$ & - & $5.35(\mathrm{~d}, 7.1)$ & - \\
\hline NH-1 & - & 11.2 & - & 11.3 & 5,6 \\
\hline NH-7 & - & - & - & 11.2 & $4,5,8$ \\
\hline
\end{tabular}

${ }^{\mathrm{a}} \mathrm{HMBC}$ correlations are from proton(s) stated to the indicated carbon.

\section{Experimental Section}

\subsection{General Experimental Procedures}

HRESIMS (positive mode) were performed on a Thermo LTQ Orbitrap XL mass spectrometer. The spectra were recorded by infusion into the ESI source using $\mathrm{MeOH}$ as the solvent. Optical rotations were measured with a Perkin-Elmer 192 polarimeter at $589 \mathrm{~nm}$ using a $10 \mathrm{~cm}$ microcell. ECD spectra were recorded on an J-710 spectropolarimeter (Jasco, Tokyo, Japan) equipped with a J-710 for Windows software (Jasco). ${ }^{1} \mathrm{H}(700 \mathrm{MHz}$ and $500 \mathrm{MHz})$ and ${ }^{13} \mathrm{C}(175 \mathrm{MHz}$ and $125 \mathrm{MHz}) \mathrm{NMR}$ spectra were recorded on a Varian INOVA spectrometer; chemical shifts were referenced to the residual solvent signal $\left(\mathrm{CD}_{3} \mathrm{OD}: \delta_{\mathrm{H}}=3.31, \delta_{\mathrm{C}}=49.0 ; d_{6}\right.$-DMSO: $\left.\delta_{\mathrm{H}}=2.50, \delta_{\mathrm{C}}=39.0\right)$. Homonuclear ${ }^{1} \mathrm{H}$ connectivities were determined by COSY experiments. Through-space ${ }^{1} \mathrm{H}$ connectivities were evidenced using a ROESY experiments with a mixing time of $500 \mathrm{~ms}$. Two and three bond ${ }^{1} \mathrm{H}_{-}{ }^{13} \mathrm{C}$ connectivities were determined by gradient $2 \mathrm{D}$ HMBC experiments optimized for a ${ }^{2,3} J$ of $8 \mathrm{~Hz}$.

\subsection{Collection, Extraction and Isolation}

Specimens of $A$. polypoides were collected in the Bay of Calvi (Corsica, France), frozen immediately and kept frozen until extraction. A reference specimen was deposited at the Dipartimento di Chimica delle Sostanze Naturali, University of Naples "Federico II". Fresh thawed animals (105.2 g 
dry weight after extraction) were homogenized and extracted twice with $\mathrm{MeOH}$ and, then, twice with $\mathrm{CHCl}_{3}(4 \times 500 \mathrm{~mL})$. Extracts were combined and concentrated; the resulting aqueous residue was then partitioned between $\mathrm{H}_{2} \mathrm{O}$ and $n-\mathrm{BuOH}$. Separation of the organic phase (13.0 g) was achieved by reversed-phase silica gel (RP18) MPLC, using a gradient elution $\left(\mathrm{H}_{2} \mathrm{O} \rightarrow \mathrm{MeOH} \rightarrow \mathrm{CHCl}_{3}\right)$. Ten fractions (A-L) were obtained, each of them was subjected to a rapid ${ }^{1} \mathrm{H}-\mathrm{NMR} / \mathrm{ESIMS}$-based analysis. Fraction $\mathrm{B}$, eluted with $\mathrm{H}_{2} \mathrm{O} / \mathrm{MeOH}$ 9:1 v/v, (3.4 g) was re-chromatographed under medium pressure on a RP18 column eluting with a linear gradient of $\mathrm{MeOH}$ (from $2 \%$ to $100 \%$ ) in $\mathrm{H}_{2} \mathrm{O}$, thus affording twelve fractions (1-12). Fraction 8 (219 mg), eluted with $\mathrm{H}_{2} \mathrm{O} / \mathrm{MeOH} 92: 8 \mathrm{v} / \mathrm{v}$, was separated by HPLC on a Synergy Polar-RP $4 \mu \mathrm{m}$ column $(250 \times 4.60 \mathrm{~mm})$ eluting with $\mathrm{H}_{2} \mathrm{O} / \mathrm{MeOH}(98: 2$, v/v) and $0.1 \% \mathrm{TFA}$, to give compounds $7(22.3 \mathrm{mg})$ and $8(4.0 \mathrm{mg})$. Fraction 10 (55.8 $\mathrm{mg})$, eluted with $\mathrm{H}_{2} \mathrm{O} / \mathrm{MeOH}(85: 15$, v/v) was separated by HPLC in the same conditions as above, to give 9 (7.8 $\mathrm{mg})$ and 10 (4.8 mg). Fractions $\mathrm{C}$ and $\mathrm{D}$, both eluted with $\mathrm{H}_{2} \mathrm{O} / \mathrm{MeOH}$ 7:3 v/v, were combined (524.5 mg) separated by HPLC on a Synergy Polar-RP $4 \mu \mathrm{m}$ column $(250 \times 4.60 \mathrm{~mm})$ eluting with $\mathrm{H}_{2} \mathrm{O} / \mathrm{MeOH}$ $(98: 2, \mathrm{v} / \mathrm{v})$, to give axityrosinium $(1,52.0 \mathrm{mg})$, axiphenylalaninium $(2,19.2 \mathrm{mg})$, polyaxibetaine (3, $6.0 \mathrm{mg})$ and compound $\mathbf{6}(9.1 \mathrm{mg})$.

The hydrophilic extract (42.7 g) was subjected to Droplet Counter Current Chromatography (DCCC), using a mixture of $\mathrm{BuOH}-$ Acetone- $\mathrm{H}_{2} \mathrm{O}$ (3:1:5) as the solvent, in the ascending mode. The flow rate of the mobile phase was adjusted to $25 \mathrm{~mL} / \mathrm{h}$; a total of 150 fractions of $8 \mathrm{~mL}$ each were collected and, as for the organic extract, analyzed by ${ }^{1} \mathrm{H}-\mathrm{NMR} / \mathrm{ESIMS}$ for the rapid detection of PIAs. Fractions 40-50 were combined, the solvent was evaporated, and the residue (300 $\mathrm{mg}$ ) was chromatographed by HPLC on a Synergy Polar-RP $4 \mu \mathrm{m}$ column $(250 \times 4.60 \mathrm{~mm})$ eluting with $\mathrm{H}_{2} \mathrm{O} / \mathrm{MeOH}(98: 2, \mathrm{v} / \mathrm{v})$ and $0.1 \%$ TFA, thus affording pure $5(16.4 \mathrm{mg})$.

Compound 5: $[\alpha]_{\mathrm{D}}+7.59(\mathrm{MeOH}, c=0.005$; HRESI-MS (positive ion mode): $m / z=210.1130$ $[\mathrm{M}+\mathrm{H}]^{+}, 232.0950[\mathrm{M}+\mathrm{Na}]^{+} ;{ }^{1} \mathrm{H}$ and ${ }^{13} \mathrm{C} \mathrm{NMR}$ data $\left(\mathrm{CD}_{3} \mathrm{OD}\right)$ are reported in Table 1.

Compound 8: $[\alpha]_{\mathrm{D}}+1.70(\mathrm{MeOH}, c=0.003)$; HRESI-MS (positive ion mode): $m / z=283.0673$ $\left.[\mathrm{M}+\mathrm{H}]^{+}, 265.0567\left[\mathrm{M}-\mathrm{H}_{2} \mathrm{O}+\mathrm{H}\right]\right]^{+} ;{ }^{1} \mathrm{H}$ and ${ }^{13} \mathrm{C}$ NMR data $\left(d_{6}\right.$-DMSO) are reported in Table 2.

\subsection{Computational Details}

A preliminary conformational search for one of the two enantiomers of $\mathbf{5}$ was performed by Simulated Annealing in the INSIGHT II package. The MeOH solution phases were mimicked through the value of the corresponding dielectric constant. Using the steepest descent followed by quasi-Newton-Raphson method (VA09A) the conformational energy was minimized. Restrained simulations were carried out for 500 ps using the CVFF force field as implemented in Discover software (Accelrys, San Diego, USA). The simulation started at $1000 \mathrm{~K}$, and then the temperature was decreased stepwise to $300 \mathrm{~K}$. The final step was again the energy minimization, performed in order to refine the structures obtained, using the steepest descent and the quasi-Newton-Raphson (VA09A) algorithms successively. Both dynamic and mechanic calculations were carried out by using $1(\mathrm{kcal} / \mathrm{mol}) / \AA 2$ flat well distance restraints. One hundred structures were generated. To simulate the solvent chosen for NMR analysis, a distance-dependent dielectric constant set to the value of $\mathrm{MeOH}$ ( $\varepsilon$ 32.63) was used during the calculations. All optimizations were performed with the software 
package Gaussian 03, by using the DFT functional RB3LYP and the basis set 6-31G(d). The B3LYP/6-31G(d) harmonic vibrational frequencies were further calculated to confirm their stability. Rotatory strength values for the electronic transitions from the ground state to the singly excited states for all conformers of $S-\mathbf{5}$ were obtained by TDDFT calculations RB3LYP/6-31G(d,p) with Gaussian 03 . The rotatory strength values were summed after a Boltzmann statistical weighting and $\Delta \varepsilon$ values were calculated by forming sums of Gaussian functions centered at the wavelengths of the respective electronic transitions and multiplied by the corresponding rotatory strengths. The ECD spectra that was obtained was UV-corrected and compared with the experimental one.

\section{Conclusions}

While highlighting the uncommon chemodiversity of $A$. polypoides, these results pointed out that the sponge does not elaborate PIAs. This finding is in agreement with the results of a recent investigation on the chemical defense of $A$. polypoides and the co-occurring species $A$. verrucosa, against microbial fouling and in feeding deterrence of a potential predator [24], activities which are believed to be mediated by PIAs [1,2]. This study indicated in A. polypoides neither chemical defense against microbial fouling nor chemically mediated feeding deterrence activity. In contrast, the sympatric sponge $A$. verrucosa has a chemical defense which, as in many other species of the genera Axinella and Agelas, is mediated by its bromopyrrole compounds [25-27], such as hymenidin, which exhibits multiple defensive roles [24]. Recent studies have reported on the phylogenetic status of the genus Axinella [28], which is difficult to define on the basis of its morphological character and includes a heterogeneous assemblage of species. A new phylogenetic hypothesis of Axinellidae and Axinella, based on two independent molecular markers (18S and 28S rRNA), has been proposed. In this taxonomic reconstruction, A. polypoides and $A$. vaceleti belong to a distinct clade (Axinellidae ${ }^{\mathrm{P}}$ ) than Axinella verrucosa; this latter sponge is now included in a new clade, named Cymbaxinella ${ }^{\mathrm{P}}$, which could be interpreted also as a new genus. The new clade Cymbaxinella ${ }^{\mathrm{P}}$ constitutes a well supported clade sister-group to Agelas $^{\mathrm{P}}$, according to the chemotaxonomic hypothesis proposed by Braekman et al. [29] on the basis of the presence of pyrroles. The clades Agelas $^{\mathrm{P}}$ and Cymbaxinella $^{\mathrm{P}}$ constitute a new clade: Agelasida ${ }^{\mathrm{P}}$. Our results, thus, provide a chemotaxonomic support for the above mentioned molecular analysis, demonstrating that $A$. polypoides does not contain pyrroles, whereas it shares with $A$. vaceleti the presence of diketopiperazine derivatives.

\section{Acknowledgments}

This research was funded by the EU's 7th Framework Programme FP7/2007-2013 under grant agreement $n^{\circ} 229893$ (NatPharma) and by MIUR (PRIN-2009).

\section{References}

1. Kelly, S.R.; Jensen, P.R.; Henkel, T.P.; Fenical, W.; Pawlik, J.R. Effects of Caribbean sponge extracts on bacterial attachment. Aquat. Microb. Ecol. 2003, 31, 175-182. 
2. Richelle-Maurer, E.; De Kluijver, M.J.; Feio, S.; Gaudencio, S.; Gaspar, H.; Gomez, R.; Tavares, R.; Van de Vyver, G.; Van Soest, R.W.M. Localization and ecological significance of oroidin and sceptrin in the Caribbean sponge Agelas conifera. Biochem. Syst. Ecol. 2003, 31, 1073-1091.

3. Forte, B.; Malgesini, B.; Piutti, C.; Quartieri, F.; Scolaro, A.; Papeo, G. A submarine journey: The pyrrole-imidazole alkaloids. Mar. Drugs 2009, 7, 705-753.

4. Cimino, G.; De Stefano, S.; Minale, L. Occurrence of hydroxyhydroquinone and 2-aminoimidazole in sponges. Comp. Biochem. Physiol. B 1974, 47, 895-897.

5. Minale, L.; Sodano, G. Marine sterols. 19 Norstanols from the sponge Axinella polyoides. J. Chem. Soc. Perkin Trans. 1 1974, 15, 1888-1892.

6. De Rosa, M.; Minale, L.; Sodano, G. Metabolism in porifera-V, biosynthesis of 19-norstanols: Conversion of cholesterol into 19-norcholestanols by the sponge Axinella polypoides. Experientia 1975, 31, 758-759.

7. Crist, B.V.; Djerassi, C. Minor and trace sterols in marine invertebrates 47. A re-investigation of the 19-nor stanols isolated from the sponge Axinella polypoides. Steroids 1983, 42, 331-343.

8. Buck, F.; Schulze, C.; Breloer, M.; Strupat, K.; Bretting, H. Amino acid sequence of the D-galactose binding lectin II from the sponge Axinella polypoides (Schmidt) and identification of the carbohydrate binding site in lectin II and related lectin I. Comp. Biochem. Physiol. Part B 1998, 121, 153-160.

9. Gabant, M.; Martin, M.; Moriou, C.; Ermolenko, L.; Guerineau, V.; Retailleau, P.; Thoison, O.; Boury-Esnault, N.; Perez, T.; Al-Mourabit, A. Axiphenylalaninium and axityrosinium, modified amino acids from the Mediterranean marine sponge Axinella polypoides. J. Nat. Prod. 2009, 72, $1875-1878$.

10. Hofsteenge, J.; Mueller, D.R.; de Beer, T.; Loeffler, A.; Richter, W.J.; Vliegenthart, J.F.G. New type of linkage between a carbohydrate and a protein: C-glycosylation of a specific tryptophan residue in human RNase Us. Biochemistry 1994, 33, 13524-13530.

11. Capon, R.J.; Trotter, N.S. $N^{3}, 5^{\prime}$-cycloxanthosine, the first natural occurrence of a cyclonucleoside. J. Nat. Prod. 2005, 68, 1689-1691.

12. Garcia, A.; Lenis, L.A.; Jimenez, C.; Debitus, C.; Quiñoa, E.; Riguera, R. The occurrence of the human glycoconjugate C2- $\alpha$-D-mannosylpyranosyl-L-tryptophan in marine ascidians. Org. Lett. 2000, 2, 2765-2767.

13. Tsujino, I.; Yabe, K.; Sekikawa, I.; Hamanaka, N. Isolation and structure of a mycosporine from the red alga Chondrus yendoi. Tetrahedron Lett. 1978, 16, 1401-1402.

14. Takano, S.; Uemura, D.; Hirata, Y. Isolation and structure of a new amino acid, palythine, from the zoanthid Palythoa tuberculosa. Tetrahedron Lett. 1978, 26, 2299-2300.

15. Chen, G.S.; Chen, C.S.; Chien, T.C.; Yeh, J.Y.; Kuo, C.C.; Talekar, R.S.; Chern, J.W. Nucleosides. IX. Synthesis of purine $N^{3}, 5^{\prime}$-cyclonucleosides and $N^{3}, 5^{\prime}$-Cyclo-2', $3^{\prime}$-seconucleosides via mitsunobu reaction as TIBO-like derivatives. Nucleosides Nucleotides Nucleic Acids 2004, 23, 347-359.

16. Broberg, A.; Kenne, L.; Pedersen, M. In situ identification of major metabolites in the red alga Gracilariopsis lemaneiformis using high-resolution magic angle spinning nuclear magnetic resonance spectroscopy. Planta 1998, 206, 300-307.

17. Aiello, A.; Fattorusso, E.; Luciano, P.; Menna, M.; Vitalone, R. Polyaxibetaine, an amino acid derivative from the marine sponge Axinella polypoides. J. Nat. Prod. 2010, 73, 620-622. 
18. Izumida, H.; Imamura, N.; Sano, H. A novel chitinase inhibitor from a marine bacterium, Pseudomonas sp. J. Antibiot. 1996, 49, 76-80.

19. Vergne, C.; Boury-Esnault, N.; Perez, T.; Martin, M.; Adeline, M.; Tran Huu Dau, E.; Al-Mourabit, A. Verpacamides A-D, a sequence of C11N5 diketopiperazines relating cyclo(Pro-Pro) to cyclo(Pro-Arg), from the marine sponge Axinella vaceleti: Possible biogenetic precursors of pyrrole-2-aminoimidazole alkaloids. Org. Lett. 2006, 8, 2421-2424.

20. McCann, D.M.; Stephens, P.J. Determination of absolute configuration using density functional theory calculations of optical rotation and electronic circular dichroism: Chiral alkenes. J. Org. Chem. 2006, 71, 6074-6098.

21. Aiello, A.; Fattorusso, E.; Imperatore, C.; Luciano, P.; Menna, M.; Vitalone, R. Aplisulfamines, new sulfoxide-containing metabolites from an Aplidium tunicate: Absolute stereochemistry at chiral sulfur and carbon atoms assigned through an original combination of spectroscopic and computational methods. Mar. Drugs 2012, 10, 51-63.

22. Petrovic, A.G.; Navarro-Vazquez, A.; Alonso-Gomez, J.L. From relative to absolute configuration of complex natural products: Interplay between NMR, ECD, VCD, and ORD assisted by ab initio calculations. Curr. Org. Chem. 2010, 14, 1612-1628.

23. Frisch, M.J.; Trucks, G.W.; Schlegel, H.B.; Scuseria, G.E.; Robb, M.A.; Cheeseman, J.R., Jr.; Montgomery, J.A.; Vreven, T.; Kudin, K.N.; Burant, J.C.; et al. Gaussian 03, Revision B. 05; Gaussian Inc.: Wallingford, CT, USA, 2004.

24. Haber, M.; Carbone, M.; Mollo, E.; Gavagnin, M.; Ilan, M. Chemical defense against predators and bacterial fouling in the Mediterranean sponges Axinella polypoides and A. verrucosa. Mar. Ecol. Prog. Ser. 2011, 422, 113-122.

25. Cimino, G.; De Stefano, S.; Minale, L.; Sodano, G. Metabolism in Porifera-III. Chemical patterns and classifications of the Desmospongiae. Comp. Biochem. Physiol. 1975, 50B, 279-285.

26. Aiello, A.; D’Esposito, M.; Fattorusso, E.; Menna, M.; Muller, W.E.G.; Perovic-Ottstadt, S.; Schroder, H.C. Novel bioactive bromopyrrole alkaloids from the Mediterranean sponge Axinella verrucosa. Bioorg. Med. Chem. 2006, 14, 17-24.

27. Haber, M.; Carbone, M.; Ilan, M.; Gavagnin, M. Structure of debromo-carteramine A, a novel bromopyrrole alkaloid from the Mediterranean sponge Axinella verrucosa. Arkivoc 2010, 2, 233-239.

28. Gazave, E.; Carteron, S.; Chenuil, A.; Richelle-Maurer, E.; Boury-Esnault, N.; Borchiellini, C. Polyphyly of the genus Axinella and of the family Axinellidae (Porifera: Demospongiae ${ }^{p}$ ). Mol. Phylogenet. Evol. 2010, 57, 35-47.

29. Braekman, J.C.; Daloze, D.; Stoller, C.; Van Soest, R.W.M. Chemotaxonomy of Agelas (Porifera: Demospongiae). Biochem. Syst. Ecol. 1992, 20, 417-431.

Samples Availability: Available from the authors.

(C) 2012 by the authors; licensee MDPI, Basel, Switzerland. This article is an open access article distributed under the terms and conditions of the Creative Commons Attribution license (http://creativecommons.org/licenses/by/3.0/). 